\title{
Aprendizagem por projetos e iniciação científica A uma educação popular e humanizadora
}

\author{
Caroline Lisian Gasparoni*
}

RESUMO: O artigo sistematiza experiência embasada nos pressupostos teóricos da educação popular e da epistemologia genética de Jean Piaget. Fomenta discussões sobre o valor pedagógico e educativo dessa abordagem, discute como ela pode contribuir para o desenvolvimento da humanização dos sujeitos, demonstrando que o incentivo à autoria incentiva uma postura ativa e responsável do estudante frente ao processo de aprendizagem, levando-o a conscientizar-se da realidade na qual está inserido.

Palavras-chave: Aprendizagem. Projetos. Iniciação Científica. Abordagem Pedagógica.

\section{Learning for projects and scientific initiation For a popular and humanizing education}

\begin{abstract}
The article systematizes experience based on the theoretical assumptions of popular education and the genetic epistemology of Jean Piaget. It fosters discussions about the pedagogical and educational value of this approach, and discusses how it can contribute to the development of the humanization of its subjects, demonstrating that the incentive to authorship encourages an active and responsible posture in the student towards the learning process, enabling them to become conscious of the reality into whichit is inserted.

Keywords: Learning. Projects. Scientific research. Pedagogical approach.
\end{abstract}

* Licenciada em Pedagogia pelo Centro Universitário La Salle - Canoas. Mestre em Educação pela Universidade do Vale do Rio dos Sinos. Tem experiência na área de Educação, com ênfase em Tecnologia Educacional. Possui Especialização em EAD. São Leopoldo/RS - Brasil. E-mail: <carolggasparoni@gmail.com>. 


\section{Aprendizaje por proyectos e iniciación científica}

Para una educación popular y humanizadora

RESUMEN: El artículo sistematiza una experiencia basada en las premisas teóricas de la educación popular y de la epistemología genética de Jean Piaget. Fomenta discusiones sobre el valor pedagógico y educativo de este enfoque y discute cómo este puede contribuir para desarrollar la humanización de los sujetos, demostrando que el incentivo a la autoría fomenta una postura activa y responsable del estudiante frente al proceso de aprendizaje, llevándolo a tener conciencia de la realidad en la que está inmerso.

Palabras clave: Aprendizaje. Proyectos. Iniciación científica. Enfoque pedagógico.

\section{Apprentissage par projets et initiation scientifique}

\section{Pour une éducation populaire et humanisante}

RÉSUMÉ: Larticle explore l'expérience basée sur les hypothéses théoriques de l'éducation populaire et de l'épistémologie génétique de Jean Piaget. Il favorise les discussions sur la valeur pédagogique et éducative de cette approche, discute comment elle peut contribuer au développement de l'humanisation des sujets, démontrant que le fait de se positionner comme auteur encourage une position active et responsable de l'étudiant face au processus d'apprentissage, ce qui lui permet de prendre conscience de la réalité dans laquelle il est inséré.

Mots-clés: Apprentissage. Projets. Initiation scientifique. Approche pédagogique. 


\section{Introdução}

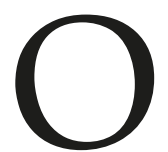

trabalho pedagógico e educativo exercido dentro das instituições escolares tem-se desenvolvido, na contemporaneidade, em meio a um cenário de desinteresse e desestimulação dos estudantes, desarticulação com as comunidades locais, críticas oriundas de setores diversos, elevados índices de repetência e evasão, dificuldades no desenvolvimento e estabelecimento de uma aprendizagem significativa, que capacite crianças e jovens a tornarem-se adultos críticos, autônomos e conscientes das mudanças necessárias ao contexto social em que se encontram, entre muitos outros desafios.

As escolas de educação básica da rede pública de ensino no Brasil vivenciam com mais intensidade esssa situação. Em um quadro de quase 30 milhões de estudantes matriculados em $2014^{1}$, os níveis de reprovação chegaram a 7\% no ensino fundamental e 13\% no ensino médio. Representam, em cada segmento, mais de 1,5 milhão de estudantes reprovados somente neste ano. No ensino médio, a evasão alcançou o índice de $8,6 \%{ }^{2}$ no mesmo período.

A necessidade de um novo olhar sobre as práticas educativas e pedagógicas, especialmente no âmbito das escolas da rede pública brasileira, torna-se evidente. Propostas pedagógicas que incentivam o desenvolvimento da aprendizagem por projetos e pela iniciação científica podem representar iniciativas que agreguem qualidade ao processo educativo e proporcionem formação mais humana e emancipadora. É possível, também, encontrar em algumas dessas iniciativas características que se aproximam dos pressupostos de uma educação popular e libertadora.

A aprendizagem por projetos representa uma abordagem pedagógica ${ }^{3}$ em que o centro do processo é o estudante, que determina o que irá ser estudado na busca por soluções às questões elaboradas também por ele. Resumidamente, concentra-se no estudante o centro da autoria, assumindo, o professor, o papel de coautor, facilitador e orientador ao longo do processo (FAGUNDES, 2000). A aprendizagem por projetos encontra seu aporte teórico na epistemologia genética, a qual alicerça seus principais pressupostos na construção e interação ativa do conhecimento. Ao longo desse artigo, narro uma experiência docente com um grupo de estudantes do ensino fundamental, em que a abordagem da aprendizagem por projetos foi desenvolvida, juntamente com a iniciativa de fomento à iniciação científica.

Esta, por sua vez, refere-se à realização de um estudo sobre determinado tema, em um contexto de escolarização básica, aproximando-se de uma pesquisa realizada nos moldes acadêmicos. O caráter de iniciação ao meio científico está presente na pouca ou nenhuma experiência no desenvolvimento de uma pesquisa fundamentada em problemática central, em referencial teórico e científico, tampouco na formulação estratégica de objetivos, hipóteses e no estudo de embasamento metodológico para realização efetiva e prática da pesquisa. No contexto escolar da educação básica, a iniciação à pesquisa e à ciência está 
intimamente conectada à abordagem da aprendizagem por projetos, visto que o principal objetivo didático a ser alcançado é levar os estudantes a aprender de forma significativa e a construir seu próprio conhecimento. Ao desenvolver sua pesquisa, os estudantes estão desenvolvendo seu próprio projeto de aprendizagem.

Em relação à qualidade da educação, os avanços são evidentes. Primeiramente, atribui-se maior significação discente às atividades escolares. Além desse aspecto, tão ou mais importante está o desenvolvimento de habilidades não somente técnicas, as quais transformam os indivíduos em especialistas ou verdadeiros depósitos humanos de conteúdos, mas também as que tangem às questões sociais e emocionais, humanizando-os. Assim, formam-se cidadãos para o mundo, com saberes que os capacitam a enfrentar e resolver os problemas globais do século XXI.

\section{Uma narrativa sobre como se aprende}

O que significa aprender? Qual suporte teórico tem-nos guiado durante nosso percurso docente e pedagógico, auxiliando-nos em uma compreensão nítida do modo como os estudantes aprendem? No decorrer de algumas décadas, muito mais se falou em como se ensina, atribuindo menor importância ao como se aprende. O ensino constitui-se, resumidamente, pelo processo feito por aquele que procura persuadir de alguma forma o outro, seja por meio de explicações, seja por meio de experiências. Entretanto, muito mais que persuação, o ensino pode significar a construção de possibilidades para o desenvolvimento da autoaprendizagem. Sob novas perspectivas, questionamos: como uma pessoa aprende? O que a estimula a aprender?

Segundo Piaget e Gréco (1974), aprendizagem é ação. Ela é o principal instrumento de construção do conhecimento. O desenvolvimento cognitivo irá ocorrer, resumidamente pela assimilação e acomodação. Diante de uma situação desafiadora, modificações podem ocorrer na mente do indivíduo que precisará construir novos saberes, desequilibrar conhecimentos e certezas anteriores, reconstruir e readaptar seus esquemas mentais e sistemas de significação. A todo esse processo denomina-se acomodação. (PIAGET, 1996). A aprendizagem somente ocorrerá quando o esquema de assimilação sofrer acomodação.

Aprender, a partir das contribuições de Piaget, torna-se uma interpretação pessoal do mundo, uma atividade individualizada em que o estudante é um sujeito ativo, desenvolvendo significados com base nas experiências vivenciadas e nas interações que estabelece com o objeto de conhecimento. Às instituições escolares incumbe propor atividades desafiadoras que provoquem desequilíbrios e reequilibrações pertinentes para a proposição de soluções aos problemas diagnosticados, estimular os estudantes a confrontá-las com os colegas, defender seus pontos de vista, argumentar e estabelecer uma discussão saudável e enriquecedora. Ao construir e propor um problema de pesquisa, o estudante já 
está elaborando novos esquemas mentais. Aliado a isso, é instigado a buscar soluções para o problema construído, combinando dados, procedimentos e resoluções. Remete-se a conhecimentos pré-estabelecidos, reflete e trabalha colaborativamente com seus colegas, principalmente quando é incentivado a trabalhar em grupos. Também verifica e corrige possíveis equívocos realizados ao longo do percurso da pesquisa.

A respeito do potencial da aprendizagem construída por projetos, Fagundes, Maçada e Sato (2000, p.16) enfatizam:

Quando o aprendiz é desafiado a questionar, quando ele se perturba e necessita pensar para expressar suas dúvidas, quando lhe é permitido formular questões que tenham significação para ele, emergindo de sua história de vida, de seus interesses, seus valores e condições pessoais, passa a desenvolver a competência para formular e equacionar problemas. Quem consegue formular com clareza um problema, a ser resolvido, começa a aprender a definir as direções de sua atividade.

Foi a partir desses pressupostos que uma escola da rede pública de ensino do município de São Leopoldo, Região Metropolitana de Porto Alegre/RS, desenvolveu o Projeto “Oficinas de Aprendizagem”. A equipe de gestão da escola havia percebido, já há algum tempo, a necessidade de explorar uma abordagem que refletisse uma nova e diferente alternativa pedagógica aos processos de ensino e aprendizagem. Propôs, assim, ao grupo docente, a delineação coletiva de um projeto para introduzir os trabalhos de iniciação científica naquele contexto escolar. Assim, um projeto baseado na abordagem da aprendizagem por projetos foi elaborado, partindo do pressuposto de que os estudantes escolheriam o tema ou assunto a partir do qual construíriam um projeto de iniciação científica.

Os estudantes de algumas turmas-piloto de $7^{0}$ a $9^{0}$ anos do ensino fundamental começaram a frequentar, no contraturno, as aulas referentes a esse projeto. Os alunos recebiam noções básicas a respeito de como realizar uma pesquisa e construir seu projeto, como também acompanhamento e apoio pedagógico sobre como desenvolver cada uma das etapas da pesquisa. Foram orientados a reunirem-se em grupos de até três estudantes cada. Após realizada a escolha do tema para a pesquisa, os estudantes precisaram escolher um professor (do quadro docente da escola) para orientá-los no desenvolvimento da pesquisa. Os professores foram procurados e o convite formalizado. Diante do aceite do professor, esse assumia a função de coautoria e, segundo Fagundes, Maçada e Sato (2000, p.22), estaria disponível para:

- Orientar projetos de investigação estimulando e auxiliando na viabilização de busca e organização de informações, face às indagações do grupo de alunos.

- Acompanhar as atividades dos alunos, orientando sua busca com perguntas que estimulem seu pensamento e reflexão, e que também provoquem: perturbações na suas certezas e nova indagações; necessidades de descrever o que estão fazendo; para testar e avaliar suas hipóteses; esforço para formular argumentos explicativos; prazer em documentar em relatórios analíticos e críticos, procedimentos e produtos, seja em arquivos locais, seja em publicações na Internet. 
- Documentar com registros qualitativos e quantitativos as constatações dos alunos sobre seu próprio aprendizado, promovendo feedback individual e coletivo.

Os problemas de pesquisa tiveram sua origem na curiosidade, dúvidas e indagações dos estudantes. Por constituição de uma abordagem da aprendizagem por projetos, muito mais que serem introduzidos ao campo do conhecimento científico, os estudantes tiveram a possibilidade de aprender conteúdos diversificados de forma pluridisciplinar, compreendendo-os como aporte teórico para o estudo e busca de respostas aos problemas. Foram, também, orientados a produzir seu registro escrito da pesquisa em um caderno de campo próprio para este fim. Elaboraram relatórios escritos no decorrer e ao término do processo de pesquisa.

Os professores envolvidos no projeto prepararam os alunos para expor sua pesquisa na "I Mostra de Iniciação Científica Interdisciplinar" ocorrida nesta escola. Os grupos utilizaram estruturas de papelão, com características próximas aos estandes utilizados em feiras da modalidade, nas quais anexaram todos os dados de pesquisa (problema, objetivos, justificativa, metodologia, conclusões etc.), com ilustrações do tema. No evento, foram escolhidos, mediante notas atribuídas por uma Comissão Avaliadora e Organizadora (composta por professores da escola não envolvidos na orientação de projetos), quatro trabalhos para representar a escola na III Mostra Municipal de Iniciação Científica do município de São Leopoldo, onde foram inscritos trabalhos provenientes de instituições escolares diversas da rede. Foi uma experiência extremamente enriquecedora para os estudantes, os quais demonstraram o desenvolvimento de autonomia, responsabilidade, autoaprendizagem, pertencimento, entre tantos outros valores e atitudes.

O Projeto "Oficinas de Aprendizagem" foi construído para atingir, em linhas gerais, o seguinte objetivo: "Desenvolver a aprendizagem através da abordagem da aprendizagem por projetos para promover uma cultura escolar de iniciação científica através do desenvolvimento processual, gradual e contínuo da proposta pedagógica apresentada.". Os objetivos específicos formulados foram:

a. Despertar o interesse pela pesquisa, introduzindo e orientando os estudantes a respeito das características de um projeto científico, sendo este composto por uma problemática central, hipóteses (certezas provisórias), objetivos geral e específico (a partir das dúvidas temporárias), metodologia de pesquisa e resultados alcançados (conclusões);

b. Estimular o desenvolvimento de aspectos investigativos e emancipatórios, levando os estudantes a refletirem e questionarem a realidade em que estão inseridos, identificando as problemáticas existentes e buscando soluções para as mesmas;

c. Instigar a criatividade, autonomia, autoria (e coautoria), entre outros aspectos importantes para o desenvolvimento do estudante a partir de uma perspectiva emancipadora;

d. Abordar os conteúdos de forma interdisciplinar, conforme a necessidade proveniente da problemática construída pelo estudante;

e. Auxiliar os estudantes na construção do seu processo de conhecimento, único e particular, instigando-os e orientando-os a realizar as leituras e estudos necessários ao desenvolvimento da pesquisa construído por eles; 
f. Qualificar a busca e produção de informações, bem como compreensão e análise das mesmas, levando o estudante a descobrir onde encontrar as informações necessárias, como interpretá-las e trabalhar com elas, realizando produções individuais a partir das mesmas. ${ }^{4}$

Ao fim da primeira etapa de formulação e realização da pesquisa, os estudantes continuaram sendo instigados a refletir sobre a realidade escolar e do bairro onde residem. Dessa forma, analisaram e registraram, por meios fotográficos, situações que os desagradavam nesse contexto e que poderiam se constituir, futuramente, em um problema de pesquisa. Tão válida como a primeira, essa etapa foi extremamente enriquecedora para a formação dos jovens. É a respeito dessas especificidades que tratamos, a seguir.

\section{Para uma escola popular e humanizadora}

A proposta pedagógica de construção em grupos de projetos de iniciação científica desperta não só o interesse dos estudantes e o processo de autoconhecimento, mas também pode estimular o surgimento de um novo olhar sobre a realidade local. $\mathrm{O}$ diferencial está na ênfase atribuída à relevância social da pesquisa, principalmente, na parte da identificação de problemas locais e da elaboração de possíveis soluções como resultado das pesquisas. Faz-se necessário que as instituições escolares abram espaço para a construção gradativa e contínua de uma nova consciência a respeito de nossa presença no mundo, alavancando um movimento contra-hegemônico em relação às práticas pedagógicas rígidas, alienantes e desconectadas de uma reflexão mais crítica sobre o ensino público. Encaminham-se, desse modo, a representação de um grupo maior de propostas alternativas e emergentes inspiradas nos preceitos da educação popular e libertadora, como também de uma concepção mais humanizadora do ato educativo.

Entretanto, o que se entende por educação popular? Apesar de existir variadas maneiras de concebê-la popular, trago as contribuições de Carrillo (2008, p.22), o qual define a educação popular como sendo:

[...] um conjunto de practivas sociales y elaboraciones discursivas em el ámbito de ela educaión cuya intencionadad es contribuir a que los diversos segmentos de las clases populares se constituyan em sujetos protagonistas de uma transformación de la sociedad em función de sus intereses y utopías.

Assim, ao colocar a educação popular na condição de um processo coletivo em busca da intervenção consciente de "sujetos históricos" na elaboração de um "proyecto liberador" (CARRILLO, 2008, p.13) que atenda aos interesses dos setores populares e seus movimentos, compremete-se com "la construción de uma nueva sociedade más justa y democrática", transformando-o em seu objetivo mestre. Constitui-se uma modalidade 
de educação quando constrói uma proposta educativa não só voltada aos interesses e necessidades das classes populares, mas, prioritariamente, intencionadora da transformação das "condiciones opressoras de la realidad actual" (CARRILLO, 2008, p. 17).

Toda abordagem pedagógica que contribui, de forma planejada e intencional, com a conscientização dos sujeitos a respeito das condições históricas, econômicas e sociais em que estão inseridos, encontra pressupostos nos princípios da educação popular. A proposta de desenvolver a aprendizagem dos estudantes por meio da elaboração de projetos de iniciação científica aproxima-se dos princípios da educação popular, ao incentivá-los a refletir sobre as conjunturas emergentes que afligem o contexto social e/ou local em que vivem. A atividade preliminar de registro fotográfico das situações críticas que prejudicam, de alguma forma, os jovens que frequentam a escola ou residem no bairro onde ela se localiza, é um exemplo de iniciativa que propicia tal reflexão. Esta, por sua vez, é desenvolvida com o objetivo de encontrar e propor meios de resolução dessas situações ou de fomento a um maior conhecimento e discussão da própria comunidade sobre elas, já que alcança, consequentemente, o âmbito familiar. Os problemas encontrados no espaço escolar, por exemplo, podem ser encaminhados à equipe de gestão da escola por meio de um relatório escrito. Com o apoio e conhecimento das famílias, abrindo as discussões e a elaboração de alternativas de solução, de forma justa e democrática, atribui-se valor igual aos diferentes segmentos da escola. A característica libertadora dessa concepção de educação está na possibilidade de libertar os sujeitos de sua condição de opressão social e psicológica, dentro de uma sociedade que se mostra, por vezes, tão injusta e desigual.

Na perspectiva humanizadora, a educação é um ato exercido pelo sujeito, uma habilidade desenvolvida por ele a qual abarca muito mais que conhecimentos técnicos, mas também comportamentos subjetivos e psicológicos que o levam a refletir sobre sua existência de forma mais profunda, porém, mais prática, possibilitando-lhe distinguir com mais clareza as causas e seus efeitos e a essência daquilo que se propõe a conhecer. Werneck (1991, p.52) denomina a essse conjunto de aptidões a serem desenvolvidas de "habilidades da consciência crítica", envolvendo as capacidades de:

[...] decodificar as mensagens, selecionar de acordo com um critério as ideias que se lhe apresentarem, as tradições e os conhecimentos científicos, e assim ultrapassar o conformismo, a comodação, a submissão, a irracionalidade para atingir a coerência entre o pensar e o agir. (WERNECK, 1991, p.52).

Assim, a educação deveria ajudar o sujeito a conhecer a si mesmo e as situações que o envolvem, a captar a essência das coisas para obter um domínio racional sobre elas e sobre os fatos desencadeados para, enfim, ter condições de posicionar-se diante da vida, fazer escolhas razoáveis de acordo com suas intenções e interesses, se autodeterminando (WERNECK, 1991). A concepção humanizadora da educação tem estreitas 
relações com uma educação popular, a qual desenvolve nos sujeitos condições para a mudança, realizada a partir deles. Tudo isso só pode ocorrer se houver a abertura para um campo de possibilidades propiciadas pelas instituições sociais que possuem como tarefa principal a educação. Nos espaços escolares, iniciativas que fomentem a reflexão, a ação autônoma e criativa, o planejamento e as estratégias mentais estarão no caminho para a concretização de uma educação popular e humanizadora. Instigar os estudantes a elaborar pesquisas com a finalidade de pensar soluções para problemas é incentivar, sobretudo, a capacidade humana de coexistir na intersubjetividade, em meio às diferenças entre as pessoas e a complexidade de compreendermos uns aos outros e aprendermos a viver em harmonia pelo bem de todos.

\section{Considerações finais}

O envolvimento dos estudantes com temas que lhes intrigam, os motivam internamente e os movem ao desejo de saber e aprender mais é transformador. Para o docente comprometido com seu dever profissional, acompanhar todo esse processo pode lhe conferir uma grande satisfação. O espírito promovido pela abordagem da aprendizagem por projetos difere em alto grau daquele que permeia o ambiente em que se desenvolvem aulas tradicionais. Os estudantes, protagonistas da seleção do que será estudado e de como se desenvolverá a aprendizagem, tornam-se autores do próprio processo de construção do conhecimento. Assim, cada indivíduo encontra espaço para utilizar seus conhecimentos prévios, construídos ao longo de sua trajetória de vida, iniciada anteriormente à sua entrada em uma instituição social escolar. Tanto quanto expressa as interpretações e impressões que possui a partir da dimensão tempo e espaço em que está imerso. Sob a perspectiva aqui proposta, a partir das interpretações e impressões construídas ele pode refletir, construir e transmitir pontos de vista e enfim, pensar sobre sua existência, única e individual.

Considerar os aspectos acima listados é conveniente ao se tomar a decisão sobre desenvolver ou não a aprendizagem por projetos. Obviamente, exige-se do profissional em educação maior dedicação, pesquisa, estudo e preparação. Far-se-á necessário que se antecipe ao estudante, se elabore estratégias que o levem a avançar em seu processo de pesquisa, dando-lhe suporte para superar os desafios no percurso daquele que se propõe a percorrer o caminho de construção de seu conhecimento. Ao longo da experiência sistematizada neste artigo, todas estas características foram observadas. De forma comum a toda nova proposta educacional vivenciada, abordar os processos de ensino e aprendizagem por projetos, incluindo a iniciação científica, surtiu efeitos positivios, porém, também, dificuldades, as quais precisaram ser superadas ao longo do caminho. Uma delas foi a não-adaptação de alguns professores à proposta. Consequentemente, 
alguns estudantes sentiram-se desmotivados e desistiram do projeto. Cerca de vinte projetos de pesquisa foram apresentados na I Mostra Interdisciplinar de Iniciação Científica. Contudo, muito mais que apresentações, ficou evidente o crescimento da cultura, da apropriação do conhecimento e da conscientização a respeito das situações que envolvem a realidade local e social em que os estudantes estão inseridos.

Trabalhar com esse modelo de abordagem pedagógica implica, consequentemente, desenvolver princípios de pertencimento, participação e inclusão. Inclusive, a própria ideia do desenvolvimento da autoria do processo de conhecimento (autoaprendizagem) auxilia na visualização dos aspectos emancipatórios que envolvem a abordagem: quando o estudante é incentivado a refletir sobre sua realidade, encontrar possíveis problemáticas e é desafiado a pensar soluções para elas, passa a desenvolver a postura de liberdade consciente e responsável, emancipando-se intelectualmente. É, portanto, levado a entender que para sermos livres, pertencermos e participarmos da sociedade em que vivemos, precisamos nos situar diante dela, conhecer a situação social na qual nascemos, vivemos, reproduzimos ou que a nós é imposta. A construção pessoal do sujeito pressupõe, ainda, o desenvolvimento de uma atitude de abertura ao mundo, de transformação da consciência, de uma visão crítica e reflexiva frente às problemáticas do cotidiano, até mesmo em nível mundial.

É considerável que o sujeito torne-se protagonista de sua própria existência e consiga, assim, atuar de forma mais livre e autônoma sobre ela. A respeito disso, Freire (1981, p.92) sabiamente se coloca: “Existir, humanamente, é pronunciar o mundo, é modificá-lo. O mundo pronunciado, por sua vez, se volta problematizado dos sujeitos pronunciantes, a exigir deles novo pronunciar.". Sob essa perspectiva, a educação popular se coloca ao lado de um projeto pedagógico libertador. Do mesmo modo, a educação humanizadora compreende a educação como um ato que vai muito além da transmissão e memorização de conteúdos e destrezas técnicas, mas todo processo que leva a constituição intelectual, social, emocional e psicológica do sujeito, instrumentalizando-o com um arsenal de conhecimentos para lidar com as mais diversas situações que enfrentará ao longo da vida.

As experiências, aliadas a um processo individual e ativo de assimilações e acomodações cerebrais, podem induzir os estudantes a aumentar a capacidade de suas funções mentais superiores por meio das construções de aprendizagens. Aquele que tiver seu interesse despertado por algo que lhe inspira, compreenderá o ato de aprender sob novas perspectivas. Ao estabelecer sentido ao que aprende, obviamente, o fará da melhor forma possível, evoluindo em sua autonomia, atenção, concentração e em sua capacidade intrínseca de autoaprendizagem. Haverá, inclusive, maior qualidade na aprendizagem desenvolvida.

A abordagem da aprendizagem por projetos, bem como o envolvimento com a iniciação científica, é uma alternativa para o incremento das condições do ensino público 
brasileiro, gerando pequenas possibilidades que possam representar o princípio da transformação da realidade escolar atual. A aliança com uma compreensão mais popular e humanizadora do processo educativo, desarticulando a reprodução dos interesses da classe dominante a que a educação tem servido há tantos anos lança uma abertura para a transformação. Trabalhar com projetos a partir das ideias e interesses que emergem dos estudantes pode significar, inclusive, a diminuição de índices preocupantes, que representam a precariedade da efetivação da função social da escola nos dias atuais.

Recebido em 12/01/2016 e aprovado em 16/03/2016

\section{Notas}

1 Informações disponíveis no Portal do Instituto Nacional de Estudos e Pesquisas Educacionais Anísio Teixeira. Endereço eletrônico: < http://portal.inep.gov.br/web/educacenso/censo-escolar>. Acesso em 04 jan. 2015.

2 Dados referentes às reprovações e evasão do ano de 2014 obtidos no site da Organização QEDU. Endereço eletrônico:< http://www.qedu.org.br/brasil/taxas_rendimento/rede-publica/rural-e-urbana?year=2014>. Acesso em 04 jan. 2015.

3 A abordagem pedagógica utiliza conceitos e estratégias para abordar ou ofertar materiais didáticos diversos, como também conteúdos que, na perspectiva dos projetos, são abordados de forma colaborativa, envolvendo a autoaprendizagem e a solução de problemas.

4 Os respectivos objetivos foram desenvolvidos pela autora do presente artigo em um projeto encaminhado à Secretaria de Educação do município de São Leopoldo. Como não houve publicações anteriores do conteúdo aqui narrado, este está livre de situações de plágio ou autoplágio.

\section{Referências}

CARRILLO, Alfonso Torres. La Educación Popular: Trayectoria y Actualidad. Bogotá: El Búcho Ltda, 2008.

FAGUNDES, Léa da Cruz; MAÇADA, Débora Laurino; SATO, Luciane Sayuri. Aprendizagens do Futuro: As Inovações Começaram! Coleção Informática para a Mudança na Educação - MEC: Brasília, 2000. Disponível em: <http://www.dominiopublico.gov.br/pesquisa/DetalhesObraForm.do?select_ action=\&co_obra $=40249>$. Acesso em 04 jan. 2016.

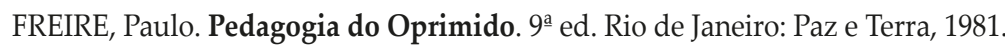

PIAGET, J.; GRÉCO, P. Aprendizagem e Conhecimento. Tradução: Equipe da Livraria Freitas Bastos. Rio de Janeiro: Freitas Bastos, 1974.

Biologia e Conhecimento. 2ª ed. Petrópolis: Vozes, 1996. 